\title{
A América Latina diante da Constituição de um Mercado Continental*
}

\section{PAULO NOGUEIRA BATISTA**}

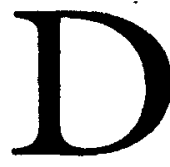

esde o princípio dos anos setenta, os países latinoamericanos se vêem deparando com uma sucessão de graves problemas de ordem internacional:

os dois choques do petróleo, a alta da taxa internacional de juros, a queda dos preços das suas matérias primas. Sob o peso de uma dívida externa asfixiante, contraída em substancial medida para fazer frente a essa constelacáo de fatores externos adversos, ficaram gravemente comprometidos na região o desenvolvimento econômico e o equilíbrio das contas governamentais. No limiar da última década deste século, para poder retomar o desenvolvimento e reestabelecer a ordem em suas finanças públicas, enfrentam adicionalmente nossos países sérias restriçóes de acesso aos mercados internacionais de capital de empréstimo e de risco; e, em razâo do aumento do protecionismo nos principais mercados desenvolvidos, tem de fazer frente também à crescentes obstáculos à comercializaçăo externa de scus produtos. Sentem-se agora ameaçados por uma tendência à discriminação econômica-comercial de que poderia decórrer uma marginalizaçáo ainda maior no cenário internacional.

Não obstante tais dificuldades, os países latino-americanos acham-se empenhados num processo de abertura de suas economias aos investimentos e aos produtos estrangeiros, convencidos que estáo de que essa é a melhor senáo a única maneira de modernizá-las e de torná-las mais competitivas internacionalmente. A forma de levar adiante uma maior inserção na economia mundial é hoje portanto uma questáo de primeira ordem ná América Latina. Como realizá-la! Pela via multilateral e não discriminatória do GATT ou pelo caminho dos

\footnotetext{
* Conferência feita pelo autor no dia 04 de setembro de 1990, no Instituto de Estudos Avançados da USP.

** Paulo Nogucira Batista é diplomata e ex-embaixador do Brasil na Organizaçäo das Naçōes Unidas (ONU).
} 
entendimentos bilaterais ou regionais de caráter preferencial? $\mathrm{Ou}$ através de uma combinação das duas modalidades?

Qualquer que seja o enfoque, é essencial não perder de vista que a liberalização do mercado nacional para produtos estrangeiros não pode se processar de forma unilateral; pelo contrário, deve ser conduzida pela via da negociação, de modo a buscar assegurar, pela reciprocidade, garantia para nossas mercadorias de acesso desimpedido aos mercados externos em troca da abertura do nosso próprio mercado. E exige também medidas acautelatórias de proteção da indústria nacional contra práticas comerciais desleais - subsídios, dumping - a que recorrem com agressividade países fortemente dependentes de exportaçóes. O êxito de uma política de abertura passa assim também por uma indispensável modernizaçăo da legislação de comércio exterior e dos mecanismos de sua aplicação.

A maximizaçáo dos resultados de uma abertura da economia supóe a livre circulação de bens e de capitais a nível internacional. Em outras palavras, depende do bom funcionamento de um sistema comercial e monetário de caráter multilateral, a cujas normas todos os países - de maior ou menor peso econômico - efetivamente se submetam. $O$ sistema multilateral, sobretudo no campo do comércio, vem sendo, no entanto, sujeito a fortes tensóes. Essas tensóes se originam essencialmente do fato de que os Estados Unidos, maior parceiro econômico do mundo e principal avalista do sistema, vir recorrendo de modo crescente ao protecionismo, sob a forma especial de barreiras não-tarifárias e também de manipulaçóes cambiais; tudo isso para tentar corrigir déficits de comércio exterior gerados basicamente pela falta de ajustes estruturais internos suscetiveis de reestabelecer a competividade internacional da economia norte-americana. Mais sério ainda é o risco de uma fragmentação do sistema multilateral de comércio que possa decorrer de uma opção dos Estados Unidos por acordos preferenciais, de corte bilateral ou regional. A decisão norte-americana de estabelecer em 1988 com o Canadá, por proposta deste, uma área de livre comércio foi entendida como indicaçáo preocuopante de que opçáo já teria sido feita. Em assim sendo, configurar-se-ia uma nova tendência que desestabilizaria ainda mais o sistema multilateral de livre comércio, ao adicionar o elemento discriminaçáo entre fornecedores externos ao de proteção pura e simples, "erga omnes ", do produtor nacional.

O concomitante aprofundamento do processo de integração das Comunidades Européias, que evoluem, como previsto desde sua fundação, de uma união aduaneira para uma união econômica, está sendo interpretado naquele contexto como mais um indício de que 
... é essencial não perder de vista que a liberalização do mercado nacional para produtos estrangeiros não pode se processar de forma unilateral;

seria inexorável a tendência ao colapso do sistema multilateral de comércio. "Mega-blocos" emergiriam em torno dos novos polos de poder econômico mundial: um europeu, sob o comando da CEE; outro asiático, liderado pelo Japão; e, na América do Norte, um terceiro formado pelo Canadá e o México em volta dos Estados Unidos. Os mega-blocos constituiriam, nessa visão, uma consequência mais ou menos inevitável da multipolaridade econômica deste final de século, no qual os Estados Unidos já não detém a condiçăo de única super-potência econômica.

A percep̧̧áo pessimista da inexorabilidade de um iminente colapso do sistema comercial multilateral representado pelo GATT tem tido bastante difusão na América Latina. Firmou-se na região o temor de que esta seria com muita probabilidade posta à margem dos prováveis grandes blocos desenvolvidos e afastada conseqüentemente das grandes correntes de intercâmbio internacional. Isso no preciso momento em que os países da área se aprestam para aumentar o seu grau de relacionamento com a economia mundial. Esse receio da regiáo de se ver relagada à periferia, se exprime, no mais das vezes, curiosamente, num inadequado tom de queixume e de passividade característico de países subdesenvolvidos que năo sabem ou năo conseguem se colocar como atores no cenário internacional. Esse sentimento latino-americano de impotência se agravou com o fim da guerra-fria, ao se definir uma nítida prioridade, pelo menos por parte da Europa Ocidental, no tocante à re-construçāo da Europa Oriental, vista como novo concorrente da América Latina na disputa por mercados e capitais.

É no quadro fluído e complexo de desideologização das relaçōes internacionais e de rearrumaçăo das relaçóes de poder no plano econômico internacional que se situa a decisão do Presidente dos Estados Unidos de anunciar em 27 de junho último uma nova política econômica para os países do hemisfério, política em que admite como objetivo final de longo prazo a possibilidade de uma integração econômica continental.

\section{A "Iniciativa Bush" se dirige essencialmente aos países} sul-americanos aos quais acenam os Estados Unidos, como primeiro passo na direção de um mercado continental; com a perspectiva de acordos bilaterais semelhantes àquele recém-pactado com o Canadá $\mathrm{e}$ ao já admitido em princípio com o México. Dada a relevância para os países sul-americanos de suas relaçóes com os Estados Unidos, a iniciativa náo pode deixar de ser um evento significativo; requer uma resposta séria, a ser dada sem afobação, à luz de uma avaliaçăo realista 
dos prós e dos contra do que efetivamente foi proposto. A conveniência de se assim proceder - sem preconceitos negativistas ou expectativas desmesuradas - é tanto maior quanto a forma de reagir ao componente central da "Iniciativa Bush" - a possibilidade de algum tipo de integraçáo econômica com os EUA - repercutirá, de uma maneira ou de outra, sobre o modo pelo qual a regiāo pretende acentuar sua inserçáo na economia mundial.

O anúncio do "Empreendimento para as Américas", definida em termos muito genéricos, pegou desprevinidos os Governantes latino-americanos. Mas não surpreendeu apenas a eles. Constituiu surpresa também para os próprios grupos de interesse norte-americanos com raízes na América Latina que vinham trabalhando em Washington por uma redefinação da política em relação à região mas que não a esperavam tão súbita. Tais grupos advogavam o deslocamento da ênfase da atitude dos EUA no hemisfério dos aspectos políticos-ideológicos para a área da cooperação econômica e que propugnam que esta năo se deve limitar aos vizinhos imediatos na América Setentrional.

O inopinado do anúncio se deveu aparentemente à preocupação do Presidente Bush de chegar a Houston, logo a seguir, na reunião de cúpula dos 7 países industrializados,com uma indicaçáo de que Washington, da mesma forma que a Europa Ocidental em relação à Oriental e ao Japão no tocante à Ásia, tinha também umá área imediata de influência. A Bush pareceu importante adotar tal postura no momento em que os EUA já não mais se sentiam em condiçóes de conter a decisão de países da Europa Ocidental - leia-se principalmente a República Federal da Alemanha - de fornecer assistência econômica bilateral à URSS e à Europa Oriental nem de obstar a retomada pelo Japão da colaboração do mesmo terreno com a China.

O anúncio da "Enterprise for the Americas" não foi precedido de consultas prévias na região, assumindo cunho inegavelmente paternalista. O Governo norte-americano pareceu, aliás, mais preocupado em buscar um "ensosso" ou "reconhecimento" pela CEE e pelo Japão da condição de preeminência norte-americana no Continente. Num contexto de formalização de áreas de influência econômica que parecem emergir da Cúpula de Houston, a iniciativa Bush pode ser interpretada como uma tentativa de demonstrar, para os latino-americanos de que os Estados Unidos reconhecem ter responsabilidades regionais, e, para as potências econômicas extra-regionais, de que estariam dispostos a exercer tais responsabilidades, se necessário, de forma preferencial. Nessa visão, o 
...os Estados

Unidos

parecem bem

longe ainda de ter renunciado ao exercicio da liderança mundial tanto no plano político quanto no econômico que asstumiram ao término da II Grande Guerra. gesto norte-americano teria, no curto prazo, caráter predominantemente político.

Existem, contudo, nos EUA, grupos que defendem uma orientaçăo mais concreta em relação à América Latina. Sustentam tais correntes de opiniáo que os EUA, ao reexaminar, no quadro pós guerra-fria e das dificuldades econômicas que enfrentam, sua postura como potência de interesses globais, não deve contrair-se a ponto de se limitar, no continente, à América do Norte. Pleiteiam os que assim se posicionam um revigoramento dos laços com a América do Sul cujos países consideram ser muito mais promissores que os da Europa Oriental como economias de mercado e como democracias. Entendem além do mais que o desenvolvimento da regiáo pode vir a ser o melhor instrumento para habilitar os países latino-americanos a combater a produção de drogas e para ajudá-los a preservar o meio-ambiente. $O$ sentimento dos que assim raciocinam é o de que os EUA muito teriam a ganhar num "trade-off" em que entrariam com simples garantias de manutenção do grau de abertura de seu mercado para produtos latino-americanos e receberiam em reciprocidade um acesso preferencial no mercado dos países latino-americanos para as mercadorias, serviços e investimentos norte-americanos.

A despeito das dificuldades econômicas que enfrentam de que resulta a perda da situaçăo de única "super-potência econômica" e que podem comprometer a sua condição de única "super-potência militar", os Estados Unidos parecem bem longe ainda de ter renunciado ao exercício da liderança mundial tanto no plano político quanto no econômico que assumiram ao término da II Grande Guerra. Isso transparece de maneira muito nítida em açóes e até em pronunciamentos do Presidente dos Estados Unidos e do Departamento de Estado, claramente indicativos de que, a despeito do fim da guerra-fria, Washington continua a atribuir a mais alta prioridade à Europa no terreno político, agora sob a forma de construçáo de uma nova ordem de segurança; como também iniciativa da mesma atitude universalista é a preeminência, no plano econômico, atribuída à tarefa de remoçăo dos focos de tensão entre os países industrializados de economia de mercado.

Os acontecimentos no Oriente Médio vieram reforçar para os Estados Unidos a questáo de suas responsabilidades globais no novo cenário de distensão Leste-Oeste. A expectativa de usufruto mais ou menos tranquilo dos "peace dividends " do fim da "guerra-fria" foi brutal $e$ inopinadamente revertida. Washington náo se furtou a assumir, sem exitaçóes, naquela conturbada e estratégica área, a maior parcela de responsabilidade na defesa tanto dos interesses políticos de numerosos 
países da regiāo quanto dos interesses econômicos dos importadores de petróleo em todo o mundo. O potencial de desestabilizaçáo representado pela invasão do Kuwait pelo Iraque não permite aos Estados Unidos outra atitude senão a de uma liderança política e militar. A diferença é que a União Soviética, seu maior adversário da' véspera, não obstante concepçóes diferentes sob a forma de fazê-lo, passou agora a cooperar para a solução dos conflitos regionais e não mais a fomentá-los. No exercício dessas responsabilidades globais, os Estados Unidos se vêem obrigados, é certo, a reduzir sua liberdade de ação unilateral e, pela primeira vez, a solicitar a cooperaçáo financeira de outros países.

A persistência da vocação de liderança mundial é igualmente manifesta no empenho dos EUA de privilegiar, em sua política de comércio exterior, a Rodada Uruguai de Negociaçōes Comerciais Multilaterais. Na hipótese de não obter da Rodada Uruguai satisfação palpável para suas reivindicações na área de subsídios a produtos agrícolas ou na de novas regras sobre serviços e sobre propriedade intelectual, será difícil ao Governo norte-americano resistir às pressóes protecionistas do seu Congresso. Isto não significaria porém que os Estados Unidos se encaminhariam de forma automática e imediata para uma política discriminatória de comércio exterior, baseada em acordos preferenciais bilaterais ou mesmo regionais. A fim de evitar as fortes tensóes políticas inerentes à formaçáo de blocos econômicos e a própria ameaça que delas poderia advir para o funcionamento de um sistema financeiro internacional de que hoje dependem tão fortemente, é bem possível que os EUA, mesmo na hipótese de um indisfarçavel insucesso da Rodada Uruguai, procurem preservar uma estrutura multilateral de comércio. Isto poderia se materializar mediante, por exemplo, uma política de acordos plurilaterais, possivelmente negociados à margem do GATT, mas abertos a adesão doś países que desejassem associar-se. Somente às partes nesses novos instrumentos se aplicaria a cláusula da Naçăo-Mais-Favorecida. Em outras palavras, esta deixaria de ter o caráter de incondicionalidade com que aplicada ao resultado de negociaçóes comerciais concluídas no âmbito do GATT.

A decisão de Washington de formar com o Canadá uma área bilateral de livre comércio se deve, èm grande parte, ao desejo de sinalizar à CEE e ao Japão que os Estados Unidos teriam alternativas para o caso de um fracasso da Rodada Uruguai. Năo estariam assim, na sua visăo, condenado a trabalhar no contexto apenas do sistema multilateral de comércio consubstanciado no GATT. O acordo com o Canadá se ressente aliás de intrínsica ambivalência. Ao mesmo tempo em que foi levado adiante pelos EUA em boa parte como uma forma de pressão 
A formação de uma área de livre comércio

hemisférica $\cdot a$ modalidade proposta na "Iniciativa

Bush " para o mercado comum continental $-e ́$, portanto, un objetivo de muito longo prazo. para acelerar as negociaçóes multilaterais em Genebra, o acordo, não obstante suas limitaçóes, pode representar o ponto de partida de um movimento de desagregação do sistema de comércio multilateral.

Os Estados Unidos não ignoram essas possíveis consequiências e nem podem desejar, enquanto potência de vocação universal, o colapso do sistema multilateral de comércio em cuja fundação no post-guerra tiveram papel decisivo. Não parecem, por outro lado, ainda preparados, para aceitar a formalização, sob a liderança de outras potências, de zonas de influência econômica regional postó que o processo significaria resignar-se também às implicaçōes políticas de multipolaridade econômica deste fim de século. Não desconhecem, além disso, que certos problemas comerciais - subsídios agrícolas, por exemplo; - exigem necessariamente soluçōes multilaterais, razão pela qual foram excluídos das negociaçóes com o Canadá.

A área de livre comércio Canadá-EUA tem, em si mesmo, alcance relativamente modesto. Circunscreve-se em sua essência a formalizar uma considerável dependência econômica e comercial pré-existente, facilitadás as negociações pela equivalência dos níveis de renda, pela similaridade das legislaçóes de comércio exterior e pelo alto grau de convergência de políticas macro-econômicas dos dois países. Em matéria de barreiras não tarifárias, hoje o mais importante obstáculo ao comércio, o acordo pouco faz. Restringe-se virtualmente a eliminar, entre as partes, apenas tarifas já consolidadas no GATT a níveis muito baixos, em conseqüência de sucessivas rodadas de negociações multilaterais no âmbito do Acordo Geral de Tarifas e Comércio.

A negociação do acordo constituiu, na realidade, uma reivindicação do Canadá cujo principal objetivo foi o de buscar tratamento preferencial na aplicação pelos Estados Unidos de medidas de proteçáo do produtor norte-americano açóes anti-dumping, direitos compensatórios, quotas, - contra importaçáo de produtos estrangeiros. Em troca do que se poderia denominar de "manutenção do nível de acesso ao mercado norte-americano", fez o Canadá importantes concessóes aos EUA no âmbito extra-comercial, em matéria de tratamento de investimentos diretos e de prestação de serviços. $O$ acordo chamado de livre comércio entre os Estados Unidos e o Canadá, sendo com efeito muito limitado no próprio campo do comércio, pode ser máis propriamente descrito como uma "área livre de tarifas" do que uma "área de livre comércio"; o instrumento é claramente mais significativo no terreno extra-cơmercial, embora não chegue a poder configurar, pelas próprias limitaçōes na área do comércio, um acordo que se possá chamar de integraçáo econômica. Considerada a diferença de dimensáo das respectivas economias, é aliás 
muito difícil conceber que os EUA possa ter interesses comerciais suficientemente importantes - mesmo em relação ao Canadá - para justificar formas mais aprofundadas de integraçáo econômica que inevitavelmente representariam um cerceamento de sua autonomia de decisão em matéria de política econômica.

Não obstante a alta prioridade que tem o México para os EUA - uma extensa fronteira, fortes correntes migratórias, intenso intercâmbio comercial - coube também aquele país e não aos EUA a iniciativa de propôr negociaçóes comerciais bilaterias com vistas à formação de uma área de livre comércio. No México, a intensificação de relaçốes econômicas com os EUA foi sempre vista com reticências, constituindo uma constante da política exterior mexicana a busca de alternativas que pelo menos dissimulassem o grau de dependência já existente. A súbita e radical mudança de orientação se deve à assinatura do acordo Canadá-EUA que é visto, no México, como uma ameaça às exportaçóes mexicanas para o mercado norte-americano e à capacidade do México de atrair capitais daquela origem. Muito embora tenha aquiescido, em princípio de junho deste ano, em iniciar estudos conjuntos sobre a viabilidade de tal acordo, Bush deixou claro primeiro que nenhuma negociaçáo poderá ser começada antes de se conhecer os resultados da Rodada Uruguai e segundo que de uma eventual negociaçáo não poderá fazer parte a questão dos fluxos migratórios. George Bush reagiu com cautela ao pleito de Salinas Gortari, procedendo de modo que espelha náo só a apreensáo por parte das indústrias e dos sindicatos norte-americanos em relação aos baixos níveis de salários no México mas também a própria preferência norte-americana por um enfoque multilateral em questóes de comércio. $O$ primeiro Mandatário norte-americano não deixou, todavia, de alimentar a expectativa mexicana de um acordo. Terá com isso se poupado do ônus de uma negativa frontal a um país de interesse geo-político para os EUA ao mesmo tempo em que tinha, mais uma vez, a oportunidade, como no caso do Canadá, de sublinhar junto à CEE e ao Japão a importância de se assegurar um resultado substancial para os EUA na conclusão, ao final do ano, da Rodada Uruguai.

Nesse complexo quadro de circunstâncias políticas, econômicas e até militares, é compreensível o caráter limitado e condicional da integração econômica admitida pelos EUA na "Iniciativa para as Américas". O processo previsto para a realização do que se admite possa vir ser uma área continental de livre comércio é o da negociaçáo sucessiva de acordos preferenciais bilaterais entre os EUA e cada país latino-americano, a começar por aqueles, como o México, que já teriam completado a privatização e a abertura de suas economias. Para 
Abriro mercado

interno

unilateralmente a

produtos

estrangeiros sem garantir, pelo jogo da reciprocidade,

o acesso dos produtos

nacionais aos mercados externos é uma política de risco com efeitos desestabilizadores

os países que năo estiverem em condiçōes de canditar-se a esse tipo de entendimento, os EUA se disporia a um passo ainda mais preliminar: a assinatura de "framework agreements ", também bilaterias, que estabelecem compromissos de consultas sobre políticas no terreno dos chamados novos temas da Rodada Uruguai - investimentos diretos, propriedade intelectual e comércio de serviços. Instrumentos dessa natureza já foram recentemente concluídos com Bolívia, Colômbia e Equador e está em negociaçóes um com o Chile. A formaçáo de uma área de livre comércio hemisférica - a modalidade proposta na "Iniciativa Bush" para o mercado comum continental - é, portanto, um objetivo de muito longo prazo. O processo para sua realização é, aliás, muito complexo, baseado que está na conclusáo prévia de uma vasta rede de acordos bilaterais, que teria nos Estados Unidos o único traço de união e cujos eventuais benefícios poderiam se cancelar uns aos outros. Desse enfoque bilateral podem resultar problemas ainda mais sérios na medida em que poderá vir a constituir um impedimento a uma verdadeira integração multilateral de amplitude continental. De qualquer modo, em tese poderá entorpecer ou mesmo inviabilizar a integração a nível subregional, entre latino-americanos.

Se levarmos em consideração que o aprofundamento do movimento de integraçáo das Comunidades Européias se traduz fundamentalmente num processo de harmonização de legislaçōes nacionais sobre movimentação de capitais e sobre prestação de serviços não é provável que daí possa decorrer o temido efeito autarcizante de formaçáo, em 1992, de uma "Fortaleza Européia", com conseqüências de "desvio de comércio" de terceiros países. Haveria que levar em conta, outrossim, o possível efeito da reúnificaçáo da Alemanha sobre o processo de integração europeù. Dada a alta complementariedade das economias integrantes das Comunidades, 0 aprofundamento mais ou menos acelerado da integração, pelos ganhos de escala que proporciona, provavelmente terá um impacto positivo, de "criaçăo de comércio" para países năo-membros. Tornar-se-ia assim compatível com as próprias normas do GATT que admitem em processos de integraçăo, a exceçăo à regra da Naçăo-Mais-Favorecida. A conclusão do processo de integração comunitária sob a forma de uniảo econômica deverá trazer uma contribuição positiva para as relaçōes econômicas internacionais, tanto em termos de sua expansão quanto em termos de seu maior equilibrio; na medida em que inclua uma moeda comum, poderá proporcionar eventualmente a todos os países, membros ou năo das Comunidades Européias, um instrumento adicional aó dólar para a constituiçăo de reservas internacionais.

O interesse político e econômico dos Estados Unidos em se manter como potência de vocação mundial e as próprias tendências abertas dó 
aprofundamento da integração econômica européia podem ser lidos, portanto, como indicaçóes de que o mundo não caminharia inexoravelmente na direção de mega-blocos econômicos. A persistente resistência política na Ásia a uma hegemonia econômica japonêsa e a natureza mesma das relaçóes econômicas entre o Japão e os " tigres asiáticos", bem como a importância para todos eles do mercado norte-americano não seriam, outrossim, de molde a favorecer a formação de um bloco econômico naquela regiāo. O mais provável será a emergência na Ásia e na Oceania de uma zona de influência financeira e comercial do Japão na qual se incluiríam de alguma forma a China e a Índia.

Não há segurança, portanto, de que a nova pólítica econômica dos EUA em relação à América Latina possa ser levada aos limites máximos que ela mesmo se fixou de constituição de uma área de livre comércio continental. É duvidoso mesmo que possam ser concluídos novos acordos bilaterais do tipo firmado com o Canadá. A dúvida tem cabimento não somente por causa do conflito nos EUA entre a vocação global e regional do país. É de se prever dificuldades intrínsecas para uma integração dos Estados Unidos com países do hemisfério mesmo que o conflito de tendências seja resolvido em Washington a favor de uma opçáo regional. A grande disparidade de níveis de desenvolvimento e de dimensões das respectivas economias torna difícil a integração econômica entre os Estados Unidos e os países da região, sobretudo numa base bilateral. Isto é verdade até em relação ao México, caso $\mathrm{em}$ que a existência de fortes interesses geo-políticos e a contigüidade geográfica normalmente facilitariam um processo de integração. Um acordo entre os EUA e o México reduzirá aliás provavelmente a margem de tratamento preferencial já concedido ao Canadá pelos EUA. Esse é problema que, em princípio, só poderia ser resolvido adequadamente mediante uma triangularizaçáo das negociaçōes que abriria caminho à constituição de uma área de livre comércio para o conjunto da América do Norte.

A opçáo mexicana por uma vinculação formal e declarada com os Estados Unidos, e conseqüentemente de renúncia ao projeto nunca levado efetivamente a cabo de integraçáo com os países sul-americanos no quadro da ALADI tem consequência política importante de liberar esses países para a busca mais intensa de uma integraçáo subregional, a margem, se necessário, do próprio quadro de ALADI. A iniciativa Bush encontra, por outro lado, já em marcha, um significativo movimento de integração entre a Argentina e o Brasil que pode constituir o núcleo dessa integraçáo sul-americana. $O$ objetivo é constituir até 1994 uma área de livre comércio entre as duas naçóes porém aberta à participação de outros países do Cone Sul que estejam 


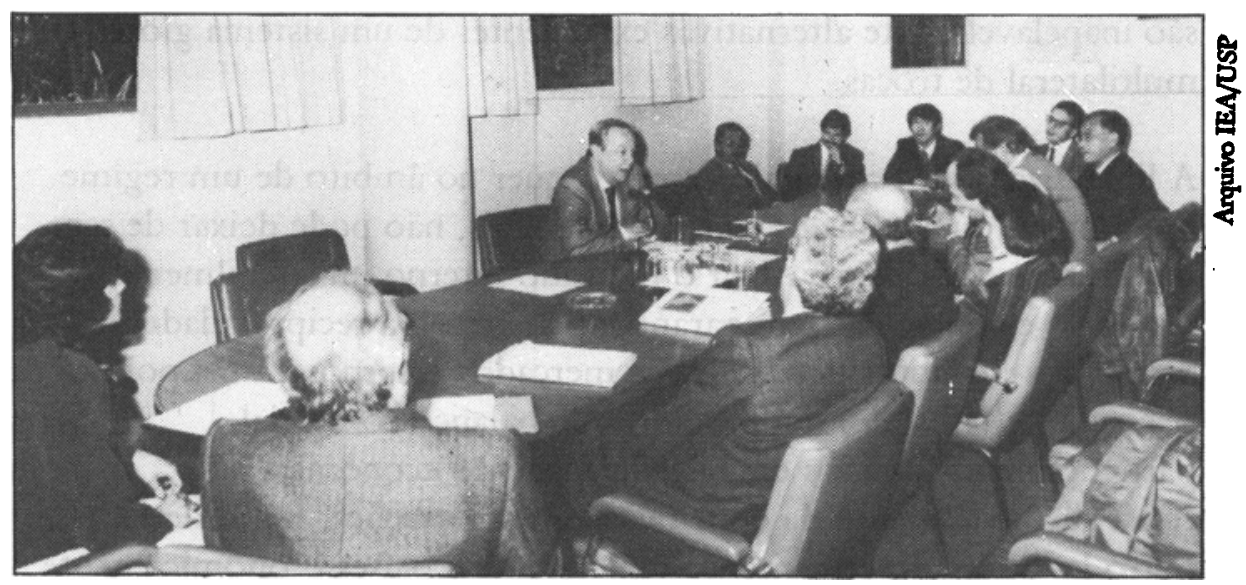

Paulo Nogueira Batista: - Os acontecimentos no Oriente Médio vieram reforçar para os Estados Unidos a questäo de suas responsabilidades globais no novo cenário de distensäo Leste-Oeste"

dispostos a compartilhar plenamente as obrigaçóes necessárias à realização daquela meta. Prosseguir nessa direção poderá ser a melhor maneira de responder à iniciativa do Presidente dos Estados Unidos de admitir, no longo prazo, uma área livre de comércio abarcando todo o continente. A integraçăo comercial entre os países sul-americanos se apresenta, de qualquer modo, mais factível em função de fatores importantes como a proximidade geográfica, a semelhança do nível de desenvolvimento dos parceiros e o relativo equilíbrio das dimensóes absolutas das respectivas economias. Vai depender, contudo, não só de vontade política mas principalmente de um mínimo de convergência de políticas macro-econômicas que viabilizem um crescimento sustentado e não-inflacionário dos países sul-americanos candidatos a integrar-se economicamente. Com recessão ou mesmo com estagnaçáo torna-se difícil tocar um processo de integração, ainda que limitado à formação de uma área de livre comércio.

Como subproduto importante dessa integração sul-americana criarar-se-iam para os países da regiáo condiçōes de negociaçáo, de forma mais equilibrada, com os Estados Unidos ou com uma eventual área de livre comércio da América do Norte, a respeiro da conveniência de uma integração em bases continentais, do Alaska à Terra do Fogo. De qualquer modo, seria fundamental assegurar em qualquer processo de integraçăo sul-americana - área de livre comércio, união aduaneira ou união econômica - o caráter positivo, "trade-creating " e não "tradt-diperting " em relaçăo a terceiros; essa é a característica capaz de preservar sua compatibilidade com os objetivos de liberalização e expansão do comércio, os quais, junto com o da náo-discriminação, constituem a essência do sistema multilateral consubstanciado no Acordo Geral de Tarifas e Comércio. Muito embora a formaçáo de áreas preferênciais de comércio náo sejam necessariamente liberalizantes de um ponto de vista global, tampouco 
são inapelavelmente alternativas excludentes de um sistema global e multilateral de trocas.

A liberalização do comércio exterior, quer no âmbito de um regime multilateral ou através de acordos bilaterais, não pode deixar de ser uma rua de duas mãos. Abrir o mercado interno unilateralmente a produtos estrangeiros sem garantir, pelo jogo da reciprocidade, $o$ acesso dos produtos nacionais aos mercados externos é uma política de risco com efeitos desestabilizadores de balanço comercial particularmente agudos em fase de expansão econômica e de conseqüente aumento da demanda por importaçóes. Equivaleria, por outro lado, um desarmamento unilateral dos países economicamente mais débeis, que os deixaria sem instrumentos para se conceder reciprocamente, em escala expressiva o tratamento preferencial, que é da essência de qualquer processo de integraçăo econômica.

A nova política econômica norte-americana para o continente contempla, além do comercial, dois outros componentes a respeito dos quais poderia haver uma manifestação mais pronta e direta dos países latino-americanos. Retiro-me às vertentes relativas a investimentos diretos na regiáo e ao seu endividamento externo. A "Investment Initiative" trata da disposição dos EUA de propor a criação no BID de um "fundo multilateral" para financiamento dos esforços de privatização na América Latina, de até US\$ $\mathbf{3 0 0}$ milhóes por ano, durante cinco anos, com recursos a serem proporcionados, em parcelas equivalentes pelos EUA, Europa Ocidental e Japão. Os números são infelizmente modestos. Teráo, além do mais, sua disponibilidade condicionada não somente à aquiescência dos contribuintes extra-continentais mas também à prévia realização de programas de ajuste econômico pelos candidatos a beneficiários. Nâo seria mais razoável destiná-los ao financiamento da integraçáo latino-americana, como etapa inicial de um processo hemisférico?

No tocante à dívida externa dos países latino-americanos, os EUA anunciaram, no contexto do "Empreendimento para as Américas" a intenção de estender aos créditos de suas agências governamentais o conceito de redução já aceito por todos os países credores para a dívida com os bancos comerciais e pelos Governos europeus em relação aos seus créditos junto aos países africanos. Os EUA indicaram ainda a intenção de admitir a aplicação do conceito de redução à própria dívida latino-americana com os organismos multilaterais de financiamento, como previsto em relaçáo a todos países em desenvolvimento endividados, com a concordância norte-americana, na "Declaração sobre Cooperaçăo Econômica" aprovada pela Assembléia Geral da ONU, em abril de 1990. Registra-se aqui um progresso 
conceitual que vale a pena traduzir em resultados concretos, muito embora a "Iniciativa Bush" especifique que esse novo tipo de redução só será concedido após haver o país candidato obtido descontos correspondentes na sua dívida com os bancos comerciais.

A "Iniciativa Bush" é, por todas razóes, um fato político suficientemente importante para justificar uma concertação entre os Ministros de Relaçóes Exteriores e de Economia dos países latino-americanos ou pelo menos sul-americanos, preparatória de uma manifestação que, em princípio, deveria ser coletiva. Assim ocorreu em 1948 quando os países da Europa Ocidental se reuniram para responder ao discurso com que o George Marshall lançou as bases do plano que levou o seu nome. $O$ gesto do presidente Bush, embora náo tenha as proporçóes e alcançe do Plano Marshall, năo pode ficar sem uma resposta articulada por parte daqueles a quem foi dirigido. Isso seria no mínimo recomendável para que nāo se frustre o início de um diálogo que a América Latina sempre desejou estabelecer e através do qual poderá firmar-se como ator e náo como mero coadjuvante nas decisōes internacionais que afetam o seu próprio destino. 